\title{
Influence of Geomagnetic Storms On VHFIonospheric ScintillationsAtNear Equatorial Station Anantapur
}

\author{
Ramamurthy.B ${ }^{1}$., Rajaratnam.S²., Nagamma.N.N³.,Thimmaiah.P³., \\ Tanveer Alam ${ }^{3}$ \\ 1.Department of Instrumentation, Sri Krishnadevaraya University, Anantapur. \\ 2.VNRVignanaJyothi College of Engg. \&Technology, Hyderabad. \\ 3. Department of Electronics, Sri Krishnadevaraya University, Anantapur.
}

\begin{abstract}
The effect of geomagnetic storms on the occurrence of ionosphere scintillations has been studiedusing the data of amplitude scintillations. To study these effects, we have analyzed VHFscintillations recorded at Anantapurduring the period March 1997 to April 1999. In the present study the scintillation data obtained from FLEETSAT radio beacon signal of $250.649 \mathrm{MHz}$ at this near equatorial station, Anantapur $\left(14.7^{\circ}\right.$ $\mathrm{N}, 77.7^{\circ} \mathrm{E}$, and Dip $15.4^{\circ} \mathrm{N}$ ) India, during some specific storm periods of varying strengths have been examined in association with the occurrence of maximum negative excursion of equatorial DST. An attempt is made to identify and delineate the effects of storms on scintillation occurrences during Pre and post Mid-night Hours.
\end{abstract}

Keywords:-Ionosphere (ionospheric irregularities), Geomagnetic storms, DST Index, Ring current

\section{INTRODUCTION}

The earth's ionosphere have many ionospheric perturbations which are sudden ionospheric disturbances, polar cap absorption, radio applications and geomagnetic storms. Thus the studies of geomagnetic storms have recently revived. The objective of the present work is to distinguish the root of magnetic storms from the sun on the upper atmosphere of the earth. The solar wind carries with it the sun's magnetic field, if it has energetic bursts, contracting and expanding the magnetosphere then geomagnetic storms can be expected. Ionosphere disturbances that cause radio and radar scintillation, disruption of navigation by magnetic compass and Auroral displays at much lower latitudes than normal. Basically an ionosphere response to storm induced changes in the neutral atmosphere. Effect of geomagnetic storms at different altitudes and latitudes differ in development of time and density. The name "geo magnetic storm" is traditional because storms had been observed first as changes of geomagnetic activity/field. The disturbance in the interplanetary medium which drives the geomagnetic storm may be due to a solar (CME) or a high speed stream of the solar wind originating from a region of weak magnetic field on the sun's surface[1,6]. During the geomagnetic storm, equatorial plasma irregularities and scintillations have been the subject of extensive investigations over the last several decades. These irregularities, which cover a very large range of scale sizes, often strongly affect the propagation of radio waves through the equatorial low latitude night-time ionosphere[2]. As VHF radio waves scintillation is extensively used to study the sub-kilometer scale size plasma density irregularities. Effect of magnetic and solar activities on ionospheric irregularities are studied so as to ascertain their role in the space weather of the near earth environment in space[3]. The amplitude measurement of VHF satellite signal at $250 \mathrm{MHZ}$ transmission from the geostationary satellite at $73^{\circ}$ degree East have been continuously monitored for the study of VHF Scintillation occurrences at the near equatorial station Anantapur.The magnetosphere cavity is created by the electrodynamics interaction between the solar wind and the earth's magnetic field [4]. The solar wind originates from the continuous hydrodynamic expansion of the solar corona and has a velocity of $400 \mathrm{~km} / \mathrm{sec}$ and a density of 1-10 atoms $/ \mathrm{cm}^{3}$ at the orbit of the during quite days. On active days, the density of the solar wind for a period of 10 hours or more may go as high as $1000 \mathrm{~km} / \mathrm{sec}$. geomagnetic storms are classified into two groups, they are storm sudden commencements type(SC) and Gradual commencements type(GC).

In the horizontal component of the earth's magnetic field $(\mathrm{H})$, in the low and middle latitude magneto grams, due to a sudden increase in the usual quite day compression of the magnetic field. The increase in the compression propagates into the surface of the earth as an elastic or hydro magnetic wave and is known as the storm sudden commencement. 
The initial phase of the storm that is between 2 to $6 \mathrm{hrs}$. There would be an increase in the amount of the geomagnetic field. This causes the newly created magnetic lines to contact rapidly and send the plasma from the magnetosphere towards the night side of the earth. This plasma injection leads to beautiful display patterns in the Polar Regions known as aurora borealis or aurora australis, also known as sub storm.

The initial phase of the geomagnetic storm is followed by the main phase of the storm which lasts for about 12 to 48 hours, in this horizontal component of the field decreases due to the inflation of the magnetic field by the incoming plasma [5]. The phase of the geomagnetic storm consists of slow draining of the plasma making the geomagnetic field to its normal state.The geomagnetic storm usually lasts for 2 to 3 days, during which the interplanetary magnetic field turns southward and remain for an prolonged period of time. Geomagnetic storms of the second type namely the Gradual Commencement type show no clear indication of the onset and hence they are called gradual commencement storms which are characterized by the main phase only. Two types of disturbance fields, the field caused by the compression of the magnetosphere and the field produced by the ring current characterize these storms $[9,10]$. The variability observed in the development of geomagnetic storms can be interpreted as due to a combination of these two fields in different ratios. Magnetic disturbances such as magnetic storms and their associated effects on the ionized and the neutral plasma of the ionosphere F-region remains one of the interesting topics of study the upper atmospheric physics [8].

\section{DATA ANALYSIS}

In order to investigate the influence of geomagnetic storms on F-layer irregularities and the resulting scintillations, VHF scintillation data from FLEETSAT radio beacon signals at $250 \mathrm{MHz}$ recorded at this near equatorial station Anantapur $\left(14.7^{\circ} \mathrm{N}, 77.7^{\circ}\right.$ and Dip $\left.15.4^{\circ} \mathrm{N}\right)$ along with the VHF scintillation data recorded at this near equatorial low latitude station in Anantapur using radio beacon signals. The storms selected are of varying intensities (severe, moderate and weak), belonging to different categories (I, II, III) occurring in different seasons (equinox, winter and summer) during the period March 1997- April 1999. The storms selected also include sudden commencement (SC) and gradual commencement types. The DST index, which is a measure of the ring current at low latitudes is taken as an index of magnetic activity in the present analysis [6].

\section{Category -I}

If the recovery phase in the DST started during the local daytime hours (preferably between 10:0016:00 hrs LT), both scintillation and spread-F activities were found to be inhibited (suppressed) completely or partially on the following night, depending on the magnitude of maximum negative excursion of the DST [7]. That is, if the maximum negative excursion of DST (peak of the magnetic storm) occurs during daytime hours preferably between 10:00-16:00 hrs LT) and well before sunset, the normal height rise of the F layer gets disturbed and hence the irregularities are inhibited on the following night.

\section{Category-II}

If the recovery phase in the DST started during the midnight-dawn (00:00-06:00 Hrs LT), strong postmidnight scintillations extending usually well beyond sunrise hours were observed at locations from $84^{\circ} \mathrm{E}$ to $122^{\circ} \mathrm{E}$ longitudes over a wide latitudinal belt up to $21^{\circ} \mathrm{N}$ [11]. That is if the maximum negative excursion of DST (peak of the magnetic storm) occurs during the midnight-dawn (00:00-06:00 Hrs LT), the F- layer height first rises and then falls which generates irregularities.

\section{Category-III}

If the recovery phase in the DST occurs during sunset-midnight (18:00- 00:00 hrs LT), the occurrence of usual night-time scintillation activity was found to be unaffected. That is if the maximum excursion of DST (peak of the magnetic storm) occurs after sunset - midnight (18:00 - 00:00 hrs LT), the F-layer height is not disturbed, and hence the irregularities occur as they do on an undisturbed night [12, 13]. However, it is found that the scintillation activity remains unaffected during the main- phase of the magnetic storm.

\section{RESULTS AND DISCUSSION}

The equatorial DST variation data, the VHF amplitude scintillation data of Anantapur (Geomag. Lat. $14.7^{\circ} \mathrm{N}$, Long. $77.6^{\circ} \mathrm{E}$ and Dip $15.4^{\circ} \mathrm{N}$ ) the peak active day of the storm for each storm are considered for the present study. The scintillation data are obtained by recording the $250 \mathrm{MHz}$ signal from FLEETSAT satellite at Anantapurand the effect of geomagnetic storm on the ionosphericscintillations are studied and analyzed as shown in table 1 .

TABLE 1 Particulars of the Geomagnetic Storms selected for the Present study 


\begin{tabular}{|c|c|c|c|c|c|c|c|c|c|c|c|}
\hline \multirow{3}{*}{$\begin{array}{l}\text { S. } \\
\text { No }\end{array}$} & \multirow{3}{*}{$\begin{array}{l}\text { Seas } \\
\text { on }\end{array}$} & \multicolumn{10}{|c|}{ Particulars of the storm } \\
\hline & & \multirow{2}{*}{$\begin{array}{l}\text { Typ } \\
\text { e } \\
\text { GC/ } \\
\text { SC }\end{array}$} & \multirow{2}{*}{$\begin{array}{l}\text { Comme } \\
\text { nc- } \\
\text { ement } \\
\text { date }\end{array}$} & \multicolumn{2}{|c|}{$\begin{array}{l}\text { Commenceme } \\
\text { nt time(hrs) }\end{array}$} & \multicolumn{2}{|c|}{$\begin{array}{l}\text { Peak } \\
\text { time(hrs) }\end{array}$} & \multirow[t]{2}{*}{$\begin{array}{l}\mathrm{H} \\
(\gamma)\end{array}$} & \multirow[t]{2}{*}{ Intensity } & \multirow{2}{*}{$\begin{array}{l}\text { DST } \\
\text { Negat } \\
\text { ive } \\
\max ( \\
\text { nT) }\end{array}$} & \multirow[t]{2}{*}{ Category } \\
\hline & & & & UT & LT & UT & $\mathrm{LT}$ & & & & \\
\hline 1 & $\begin{array}{l}\text { Equi } \\
\text { nox }\end{array}$ & $\mathrm{GC}$ & 28.03 .97 & 0800 & 1330 & 0200 & 0730 & 93 & Moderate & -55 & $\mathrm{I}$ \\
\hline 2 & $\begin{array}{l}\text { Equi } \\
\text { nox }\end{array}$ & $\begin{array}{l}\mathrm{GC} / \\
\mathrm{SC}\end{array}$ & 10.04 .97 & 1300 & 1830 & 0530 & 1100 & 113 & Severe & -80 & $\mathrm{I}$ \\
\hline 3 & $\begin{array}{l}\text { Equi } \\
\text { nox }\end{array}$ & $\begin{array}{l}\mathrm{SC} / \\
\mathrm{GC}\end{array}$ & 16.04 .97 & 1321 & 1851 & 0530 & 1100 & 82 & Moderate & -75 & $\mathrm{I}$ \\
\hline 4 & $\begin{array}{l}\text { Wint } \\
\text { er }\end{array}$ & $\mathrm{SC}$ & 10.12 .97 & 0527 & 1057 & 1630 & 2200 & 154 & Severe & -68 & II \\
\hline 5 & $\begin{array}{l}\text { Equi } \\
\text { nox }\end{array}$ & $\mathrm{SC}$ & 20.08 .98 & 1847 & 0017 & 2000 & 0130 & 163 & Severe & -86 & II \\
\hline 6 & $\begin{array}{l}\text { Equi } \\
\text { nox }\end{array}$ & $\mathrm{SC}$ & 28.02 .98 & 0500 & 1030 & 1530 & 2100 & 116 & Severe & -44 & III \\
\hline 7 & $\begin{array}{l}\text { Equi } \\
\text { nox }\end{array}$ & $\mathrm{SC}$ & 20.03 .98 & 0900 & 1430 & 1530 & 2100 & 200 & $\begin{array}{l}\text { Very } \\
\text { Severe }\end{array}$ & -109 & III \\
\hline 8 & $\begin{array}{l}\text { Equi } \\
\text { nox }\end{array}$ & GS & 25.03 .98 & 0100 & 0603 & 1630 & 2200 & 139 & Severe & -72 & III \\
\hline
\end{tabular}

Note $H(\gamma):<50$ Weak, 50-100 Moderate, 100-200 Severe, >200 Very Severe intensity

GC : Gradual Commencement

SC : Sudden Commencement

\subsection{Scintillation activity during the geomagnetic storms}

\subsubsection{The Magnetic Storm of 28th March, 1997(category-I)}

The data of equatorial DST variations, the data of VHF scintillations at Anantapur for a Five Day Period centered on the Storm Days for all the days as presented in Table 1. This storm on $28^{\text {th }}$ March, 1997 is of moderate intensity with $\mathrm{H}(\gamma)=93$ and is of gradual commencement type at $0800 \mathrm{hrs}$ UT (1330 hrs LT) on 28th March, 1997. The maximum negative excursion of DST $=-55 \mathrm{nT}$ occurred at $0200 \mathrm{hrs}$ UT (0730 hrs LT) on the following day, i.e on 29th March, 1997.

The storm belongs to Category-I as discussed in detail earlier, since the recovery phase of the storm falls during local daytime hours. The scintillation activities are present until the commencement of the storm are found to be inhibited partially after the peak at $0200 \mathrm{hrs}$ UT (0730 hrs LT)andthe storm is of moderate intensity.

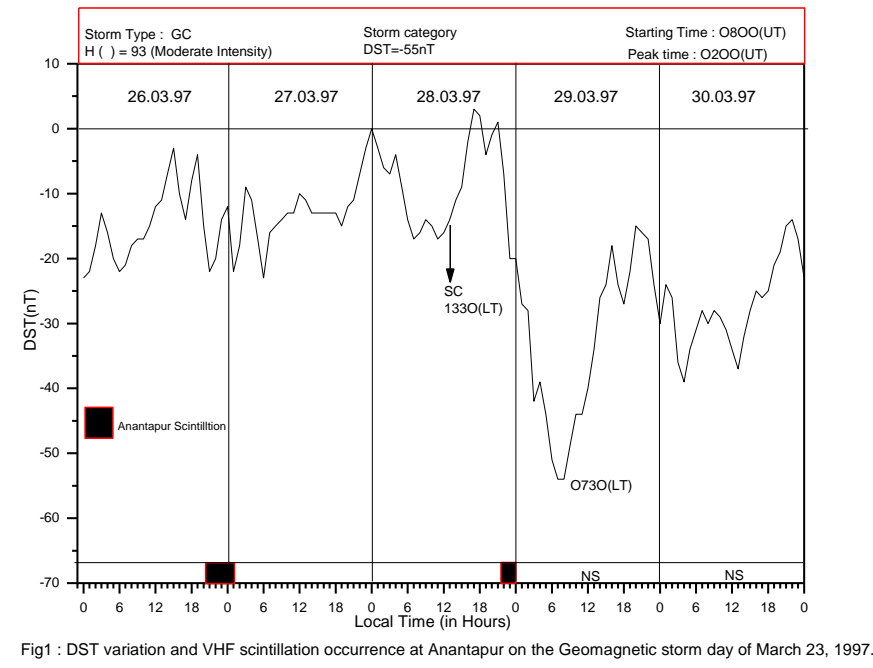

3.1.2 The Magnetic Storm of the 10th April, 1997(category-I) 
This storm on $10^{\text {th }}$ April, 1997 is of severe intensity with $\mathrm{H}(\gamma)=113$ and is of sudden commencement type with SC at $1300 \mathrm{hrs}$ UT (1830 hrs LT) on 10th April, 1997. The maximum negative excursion of DST = $80 \mathrm{nT}$ occurred at $0530 \mathrm{hrs}$ UT $(1100 \mathrm{hrs} \mathrm{LT})$ on the following day, the 11th April, 1997. Though the storm type is specified as GC in data it resembles to be SC type. This storm comes under Category-I as the recovery phase of the storm falls during local daytime hours. Both scintillations and spread-F activities present until the commencement of the storm are found to be inhibited completely after the peak activity of the storm 0530 UT (1130 hrs LT), as the storm is of severe intensity.

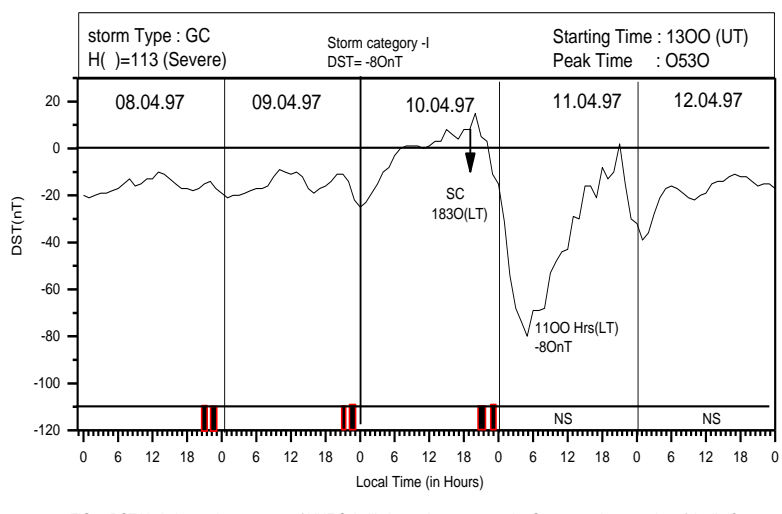

\subsubsection{The Magnetic Storm of 16th April 1997(category-I)}

This storm is of moderate intensity with $\mathrm{H}(\gamma)=82$ and is of gradual commencement type with GC at $1321 \mathrm{hrs}$ UT (1851 hrs LT) on 10th April, 1997. The maximum negative excursion of DST $=-75 \mathrm{nT}$ occurred at $0530 \mathrm{hrs}$ UT (1100 hrs LT) on the following day, the 17th April, 1997. This storm comes under Category-I as the recovery phase of the storm falls during local daytime hours. The scintillations activity present until the commencement of the storm are found to be inhibited completely after the peak activity of the storm, as the storm is of moderate intensity.

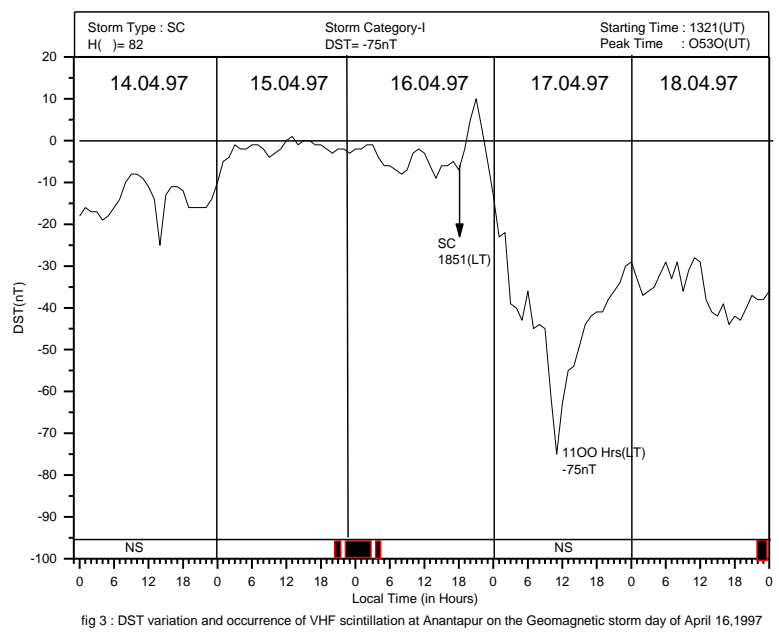

\subsubsection{The Magnetic Storm of 10th December, 1997(category-II)}

This is a typical storm of severe intensity with $\mathrm{H}(\gamma)=154$ and is sudden commencement type with SC at $0527 \mathrm{hrs}$ UT (1957 hrs LT) on 10th December 1997. The maximum negative excursion of DST exhibiting triple peak with the first peak of $-68 \mathrm{nt}$ at $1630 \mathrm{hrs}$ UT (2200 hrs LT) on 10th December, 1997; the second peak of $-65 \mathrm{nT}$ at $2200 \mathrm{hrs}$ UT $(0300 \mathrm{hrs}$ LT) on 11th December, 1997 and the third peak of $-68 \mathrm{nT}$ at $1200 \mathrm{hrs}$ UT (1730 hrs LT) on 11th December, 1997. The recovery phases of the first and the third peaks fall between sunset and midnight (1800-0000 hrs) local time. Hence, they come under Category-III, while the recovery phase of the second minor peak falls between midnight to sunrise (0000-0600 hrs) local time, falls under Category-II. However, the influence of the first and the third peaks appears to dominate over the influence of the second peak 
and hence the F-layer height-rise is not disturbed. Consequently the scintillation and spread-F activities are unaffected. This can be seen from the Fig4 that no scintillation activity observed for at least two days prior to the first peak continued for two more days after the peak activity is presented in figure 4 .

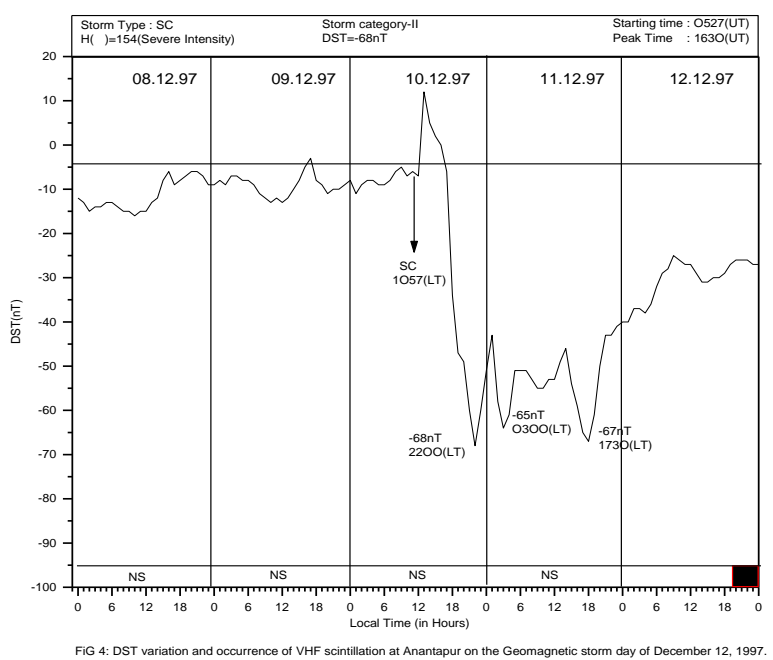

\subsubsection{The Magnetic Storm of 19th/20th August 1998(category-II)}

This storm is of severe intensity with $\mathrm{H}(\gamma)=163$ and is also a sudden commencement type with SC at $1847 \mathrm{hrs}$ UT (0017 hrs LT) on 20th August, 1998. The maximum negative excursion of DST $=-86 \mathrm{nT}$ occurred at $2000 \mathrm{hrs}$ UT (0130 hrs LT) on 21st August, 1998. This storm comes under Category-II as the recovery phase of the storm falls during local midnight to sunrise (0000-0600) hrs. The F-layer height-rises first and then falls which generates irregularities. This is a typical storm exhibiting two peaks. The first minor peak with DST = $52 \mathrm{nT}$ occurs at $0600 \mathrm{hrs}$ LT and a major peak with DST $=-86 \mathrm{nT}$ occur at $0130 \mathrm{LT}$. Since the recovery phases of both these peaks fall between midnight to sunrise hour's local time, they come under Category-II. Hence, strong post-midnight scintillations extending beyond sunrise hours are expected. However, only short duration post-midnight scintillation of about one hour were observed on 18th August, 1998, two days prior to the peak active day of the storm. The scintillation activity was found to be inhibited on 19th August, 1998, a day prior to the commencement of the storm and on 20th August, 1998, the peak active day of the storm. The pre-midnight scintillation activity was found to be triggered again on 21st and 22nd August, 1998immediately after the peak day is presented in figure 5 .

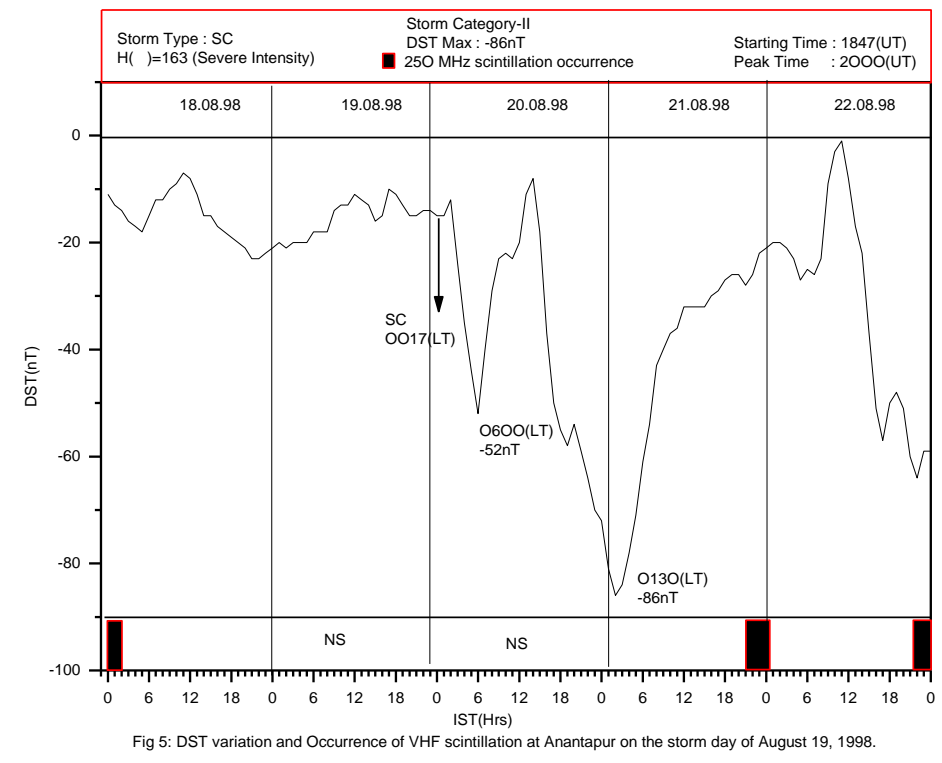


This storm comes under Category-III since the recovery phase of the storm falls between sunset and midnight (1800-0000) hour's local time, the F-layer height rise is not disturbed and hence the scintillations activity isunaffected. Strongscintillations extending over seven to eight hours are observed on 26th/27th February 1998 and 28th February/1st March and 1st/2nd March 1998.

However, there are substantial inhibitions of scintillation on 27th/28th February 1998 and 2nd/3rd March 1998 due to the presence of Minor peaks around $2130 \mathrm{hrs}$ UT (0200 hrs LT) on 27th/28th February, 1998 and also a double peak around $2100 \mathrm{hrs}$ UT and $2330 \mathrm{hrs}$ UT (0230 hrs LT and $0500 \mathrm{hrs}$ LT) since all the three minor peaks occurred between local midnight and sunrise hours they might be exhibiting the characteristic similar to the Category-I storms and hence the inhibitions in scintillation activities are observed is presented in figure 6.

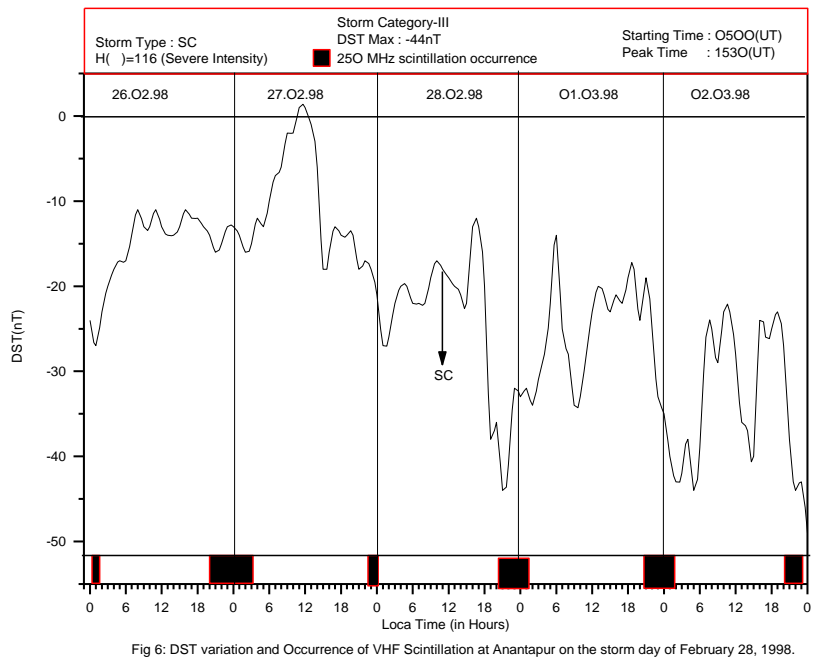

\subsubsection{The Magnetic Storm of 20th March, 1998(category-III)}

This storm is of very severe intensity with $\mathrm{H}(\gamma)=200$ and is sudden commencement type with SC at $0900 \mathrm{hrs}$ UT (1430 hrs LT) on 20th March 1998. The maximum negative excursion of DST $=-109 \mathrm{nT}$ occurred at $1530 \mathrm{hrs}$ UT (2100 hrs LT) on the following day, the 21st March 1998. This storm comes under the CategoryIII discussed in detail earlier, since the recovery phase of the storm falls after sunset and before midnight hours Local Time, the F-layer height rise is not disturbed and hence the scintillations activity is unaffected. This is clearly evident from the Fig7.

The occurrence of strong scintillations at Anantapuris two days prior to the storm peak activity continued unaffected for two more days even after the elapse of the peak activity of the storm and the storm peak activity also continued unaffected for two more days. Further, the onset of scintillations during all these storm days happened to be consistently pre-midnight hours and persisted for over seven to eight hours.

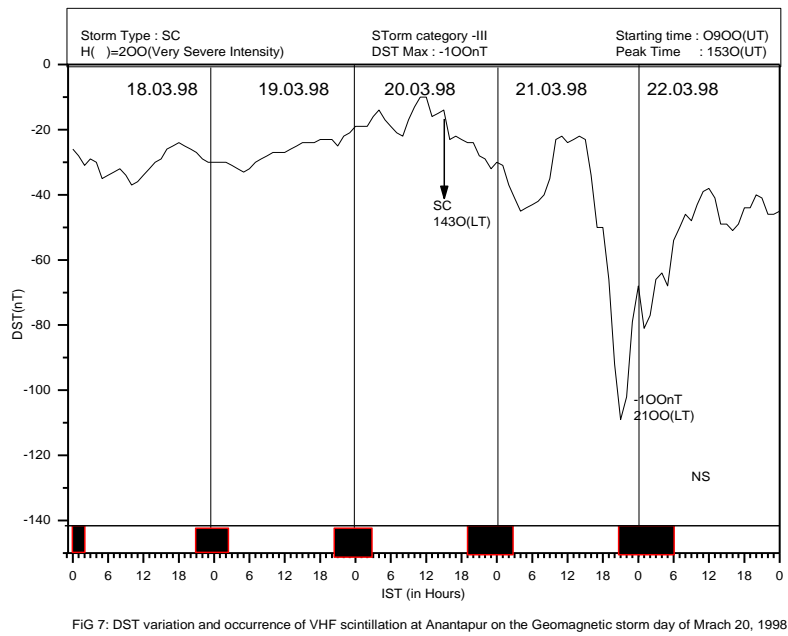

3.8. The Magnetic Storm of 25th March 1998(category-III) 
This storm is of severe intensity with $\mathrm{H}(\gamma)=139$ is a gradual commencement type with GC at $0100 \mathrm{hrs}$ UT (0630 hrs LT) on 25th March 1998 with the maximum negative excursion of DST = -72 nT occurring at $1630 \mathrm{hrs}$ UT $(2200 \mathrm{hrs}$. LT) on the following day the 25th March 1998.

This storm also comes under Category-III discussed in detail earlier. Since the recovery phase of the storm falls after sunset and before midnight hour's local time, the F-layer height-rise is not disturbed and hence the scintillations activity unaffected up to the peak day of the storm. This is clearly evident from the Fig8. Very long duration scintillations and spread $F$ were observed two to three days prior to the peak day of the storm. However, since the storm is of gradually commencing type with severe intensity, the scintillations are found to be inhibited immediately following the peak storm day. However, scintillation activity for about five hours was observed at Anantapur for one more day after the peak day before exhibiting inhibition.

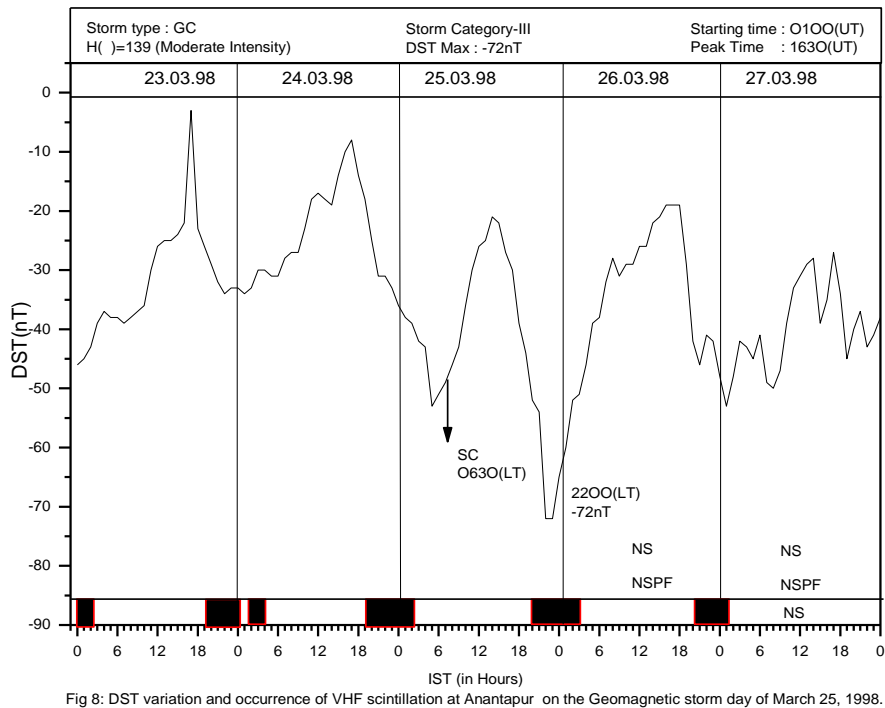

\section{SUMMARY OF RESULTS}

The observations of equatorial F-region irregularities and the likely mechanism for their generation have been reviewed by Basu and Kelley (1977). It is now believed that the irregularities originate on the steep bottom side electron density gradient. It is now accepted that the plasma bubbles generated in the process up well to the topside through a Rayleigh-Taylor Instability (RTI) mechanism. The forcing factors in the generation or inhibition of irregularities appear to be primarily at the height of the $\mathrm{F}_{2}$ layer with the possible addition of the pre-reversal drift velocity and the rate of fall of the layer. In the post sunset period equatorial $F$ region rises to higher altitudes where ion-neutral atom collision frequency is small thereby favoring the R-T instability growth. A recent study by Jayachandranet al. (1987) showed that during magnetically disturbed conditions the post sunset height rise is inhibited. The ring current may be one of the sources which directly or indirectly is related to the rise and fall of $\mathrm{F}$ layer.The storm is s belonging to Category-I, complete or partial inhibition of scintillations are observed on the nights following the occurrence of peak activity of the storm (indicated by the maximum negative excursion of the DST Index) during daytime hours. During this period, the normal height-rise of the F-layer gets disturbed and hence the irregularities responsible for causing scintillations are inhibited on the following night.During the specific case of a storm belonging to Category-II, strong postmidnight scintillations extending into the sun-rise hours are observed. This is due to the occurrence of the peak activity of the storm (indicated by the maximum negative excursion of the DST Index) during the midnight-todawn Hrs local time. This affects F-layer height, which first rises and then falls thus triggers the generation of irregularities which cause scintillations. The present results of inhibition and generation of scintillations during 3 different categories of storms is consistent with the suppressions observed by Dabaset al. (1989) and Rastogi and Woodman (1978) and the generations observed by Das Gupta et al. (1985). The results are also in conformity with the category concept proposed by Aarons (1991).

\section{REFERENCES}


[1] Kumar, S and Gwal, A. K.: VHF ionospheric scintillations near the equatorial anomaly crest: Solar and magnetic activity effects, J. Atmos.\& Solar. Terr. Phys., 62, 157-167, 2000.

[2] Rama Rao, P. V. S., Gopi Krishna. S., Niranjan, K. and Prasad, D. S. V. V. D.: Study of spatial and temporal characteristics of L- band scintillations over Indian low - latitude region and their possible effect on GPS navigation, AnnalesGeophysicae., 24, 1567-1580, 2006b.

[3] Dabas, R. S., Lal, J.B., Tyagi, T.R and Somayajulu, Y.V.: Variations of total electron content and other ionospheric parameters associated with magnetic storms, Ind. Radio Space Phys., 9, 1-6, 1980.

[4] Chimmonas, G. and G.O Hines, 1970. Planet Space Sci., 18, 583.

[5] Sugiura, M., 1964.,Annales of I.G.Y., 34, 9.

[6] Rangarajan, G. K., and Barreto, L.M.: Long term variability in solar wind velocity and IMF intensity and the relationship between solar wind parameters \& geomagnetic activity, Earth Planets Space., 52, 121132, 2000.

[7] Banerjee, P. K., R. S. Dabas, and B. M. Reddy.: C and L band transionospheric scintillation experiment: Some results for applications to Satellite Radio Systems, Radio Sci., 27(6), 955-969, 1992.

[8] Kelley. C., Michael and Makela.,Jonathan.J: By- dependent prompt penetrating electric fields at the magnetic equator, Geophysical Research Letters., 29, 57-60, 2002.

[9] Vyas, B. M., and Pandey, R.: Night-time F-region and daytime E-region ionospheric drifts measured at Udaipur during solar flares, AnnalesGeophysicae,. 22, 3513-3522, 2002.

[10] Vyas, B. M., and Pandey, R.: Effect of IMF parameters on F- region drift velocity over low latitude, Indian Journal of Radio \& Space Physics., 32, 142-147, 2003.

[11] Umaa, P.S.Brahmanandama,n, YoshihiroKakinami b, A.Dmitriev b, A.DmitrievN.S.M.P.LathaDevia, K. UdayKiran a, D.S.V.V.D.Prasad c, P.V.S.RamaRao c, KNiranjan c, Ch.SeshuBabu d, Y.H.Chu b Ionospheric responses to two large geomagnetic storms over Japanese and Indian longitude sectors, Journal of Atmospheric and Solar-Terrestrial Physics 74 (2012) 94-110.

[12] Fejer, B.G, Scherliessl and De Paulaer.:Effect of the vertical plasma drift velocity on the generation and evolution of equatorial spered F. J. Geophys. Res., 104, 1959-1970, 1999 b.

[13] Koster, , J. R.: Equatorial scintillations, Planet. Space Sci., 20, 1999-2014, 1972.

[14] Dr. U. Eranna , Dr. B. RamaMurthy, Dr. K. Bhanu Prasad, R.Manjula on effect of geomagnetic storms on VHF scintillations over near equatorial station anantapur.

[15] Sushil Kumar, Gwal, A.K.: VHF ionospheric scintillation near the equatorial anomaly crest: solar and magnetic activity effects, Journal of Atmospheric and Terrestrial Physics., 62, 157-167, 1999 .

[16] Biktash, L.Z.: Role of the magnetospheric and ionospheric currents in the generation of the equatorial scintillations during geomagnetic storms, AnnalesGeophysicae., 22, 3195-3202.2004.

[17] Biqiang Zhao, WanWeixing, Liu Libo, and Mao Tian.: Morphology in the total electron content under geomagnetic disturbed conditions: results from global ionosphere maps, AnnalesGeophysicae., 25, 15551568, 2007.

[18] Dabas, R. S., Das, R.M., Vohra, V.K and Devasia, C.D.: Space weather impact on the equatorial and low latitude F- region ionosphere over India, AnnalesGeophysicae., 24, 97-105, 2006.

[19] Das Gupta, A., Maitra, A., Das, S.K.: Post-midnight scintillation activity in relation to geomagnetic disturbances. Journal of Atmospheric and Terrestrial Physics., 47, 199-916, 1985.

[20] Das Gupta, R.S., Lakshmi, D.R., Reddy, B.M.: Effect of geomagnetic disturbances on the VHF scintillation activity at equatorial and low latitudes, Radio Science., 24, 563-573, 1989.

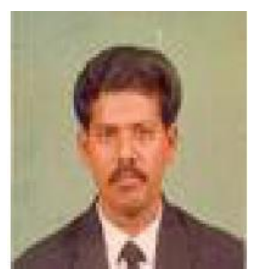

Dr.B.RamaMurthy is presently working as a Professor in the Department of Instrumentation \& USIC, Sri Krishnadevaraya University, Anantapur, Andhra Pradesh, India. He is having 23 years of Research \&Teaching experience. Under His guidance $10 \mathrm{Ph} . \mathrm{D}$ 's\&5M.Phils are awarded. His areas of interest are Embedded Systems, Network and Mobile Communications, Network security systems, Industrial Automation and Bio-medical Instrumentation. 